
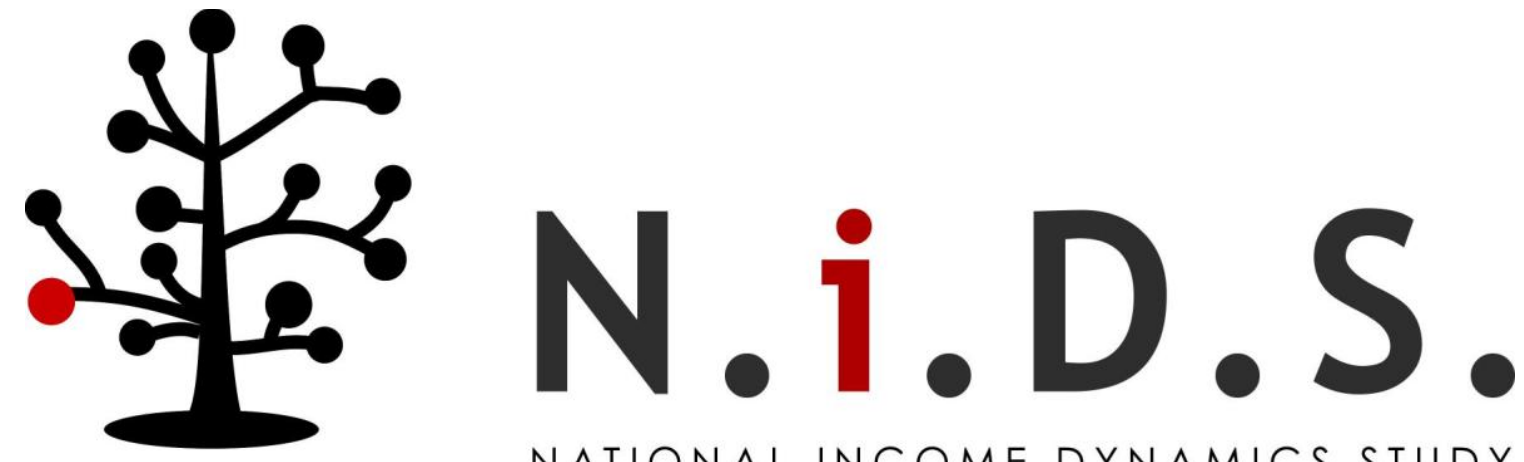

NATIONAL INCOME DYNAMICS STUDY

\title{
Social Assistance Grants: Analysis of the NIDS Wave 1 Dataset
}

\author{
Discussion Paper no. 10 \\ Hayley McEwen \\ Southern African Labour \& Development Research Unit \\ hayleyavalon@gmail.com \\ Catherine Kannemeyer \\ Development Policy Research Unit \\ kancath@gmail.com \\ Ingrid Woolard \\ Southern African Labour \& Development Research Unit \\ Ingrid.Woolard@uct.ac.za
}




\section{Introduction:}

This report summarizes the initial findings of the National Income Dynamics Survey (NIDS) regarding social assistance grants in South Africa. A comparison to various other data sources is also included in order to highlight any shortfalls or strengths in the NIDS data in comparison to previous surveys.

To date there has been no publicly available nationally representative survey which includes detailed information on social assistance received. The October Household Surveys from 1995 to 1999 include questions on whether social assistance is received and what form it takes (child support grant, disability grant etc.), and sometimes including questions on how much is received. The General Household Surveys from 2003 to 2007 include questions on what form of social assistance is received, if any. Demographic statistics on grant recipients can also be obtained from the South African Social Security Agency (SASSA) which is responsible for managing grant payments.

NIDS contributes to knowledge by including questions such as who receives the payments, how much do they receive, how long the grant has been received, whether the respondent has ever applied for a grant, why it was rejected or why they never applied. This will hopefully provide some insight into the effectiveness of the social security system and encourage further research on the topic.

This report considers social assistance for children, the elderly and the disabled in turn. It then provides some simple analysis of the importance of social assistance to poor households. 


\section{Social Assistance for Children}

Before April 1998, social assistance for children consisted of the State Maintenance Grant. This grant held onerous conditions, such as that one parent had to be deceased or maintenance had to be petitioned for in court. As such, the proportion of children in need receiving the grant was very low. After this date the new Child Support Grant was introduced, with less stringent conditions and aiming to cover more of the population in need. The value of the grant was initially lowered to R100 per month but increased over time in line with inflation and at present is worth R240 per month. The Foster Care Grant is designed to provide support for children being cared for by someone outside of their family, particularly orphans or abandoned children.

\subsection{Eligibility}

At introduction, children under the age of seven were eligible for the Child Support Grant. The age limit was raised to nine years in April 2003 and to eleven years in 2004. The age limit was again raised to under fourteen in April 2005 and at present is set at under fifteen. Eligibility is also subject to the caregiver's income falling below a set means test level to ensure only the neediest segment of the population is in receipt. Despite inflation of roughly 45\% between 1998 and 2005, the value set for the means test remained at R800 (urban) and R1100 (rural) per month from 1998 onwards. This has recently been revised and from October 2008 the means test level was to be calculated as 10 times the grant amount, to account for inflation in the future. ${ }^{1}$

The Foster Care Grant is only available to caregivers with a court order declaring their foster care status. While the Child Support Grant only applies to South African permanent residents and citizens, the Foster Care Grant additionally applies to refugees. Children under the age of 18 are eligible and eligibility can extend up until the age of 21 if the child remains a dependant of the caregiver. The value of the grant is R680 per month currently and there is no means test attached to receipt.

\footnotetext{
${ }^{1}$ Means testing for married caregivers doubles the mean test threshold and adds the spouse's income to the caregiver's income. Before October 2008, the mean test level was not adjusted for married couples. For more information on grants consult http://www.sassa.gov.za.
} 


\subsection{Sample Size and Non-response:}

The National Income Dynamics Survey sampled 7305 households, including information on 31,170 household members. Resident household members amounted to 28,255 and the remaining 2,915 non-resident household members are excluded from the subsequent analysis. ${ }^{2}$ Of these resident members, 10,005 are reported as children, defined as being under the age of 15 (roughly $35 \%$ of the sample). ${ }^{3}$ Post-stratified weights from the household derived dataset (w1_wgt) are applied to this sample so the figures are comparable with national population figures.

Every variable in the dataset contains some observations where the respondent either didn't know the answer, refused to answer the question or the data is missing/not applicable. Table 1 in the appendix contains a summary of non-response by variable for the questions regarding child grants. As can be seen, item response rates are particularly poor in the questions regarding dates. This is likely to be a recall problem since the majority of the non-response falls into the 'don't know' category for these particular questions, as opposed to other questions where the non-response consists mainly of missing values. Aside from these dates, the response rates in this section are relatively high.

\subsection{Demographics of Grant Recipients:}

Of the 9336 children under the age of 14 in the survey, 5,787 of them reported receiving some form of social assistance from the government. This corresponds to roughly 8,731,339 (58\%) children in a total population of 15,038,655 under the age of 14 receiving assistance. In 2004 the percentage of children under the age of 7 receiving assistance was $50 \%$ so take-up appears to have increased in the last four years (Woolard, Carter \& Aguero, 2005). The grant beneficiaries are split pretty evenly by gender, with 4,441,311 (51\%) being males and 4,290,028 (49\%) being females.

The purpose of child social assistance is to reach children in need, and one of the most at risk portions of the child population is orphans. Figure 1 below indicates how many orphans are currently receiving social assistance according to the NIDS data. Unfortunately there is no information on grant receipt in children over the age of 14 . What is most striking is the high

\footnotetext{
${ }^{2}$ Non-resident household members are those members that are recorded on the household roster but do not reside in the household four nights a week.

${ }^{3}$ This figure is generated using derived 'best' age (w1_best_age_year) in the individual derived dataset.
} 
number of paternal orphans receiving grants, particularly the child support grant, and the low number of maternal orphans receiving grants. This concurs with evidence found in Case, Hosegood and Lund (2004) that the probability of a child receiving a grant decreases when the mother is absent. The same conclusion is drawn in Woolard, Carter and Aguero (2005) using the KIDS data.

Children living with their widowed fathers are the least likely to be receiving grants. Unsurprisingly, orphans who have lost both parents are the most likely to be receiving the foster care grant. What is unexpected though is the fact that, aside from paternal orphans, orphans are less likely to be receiving the child support grant than children with both parents. This may be a result of the more complex documentation required without the child's mother as caregiver.

Figure 1: Percentage of children receiving social assistance, by orphanhood status

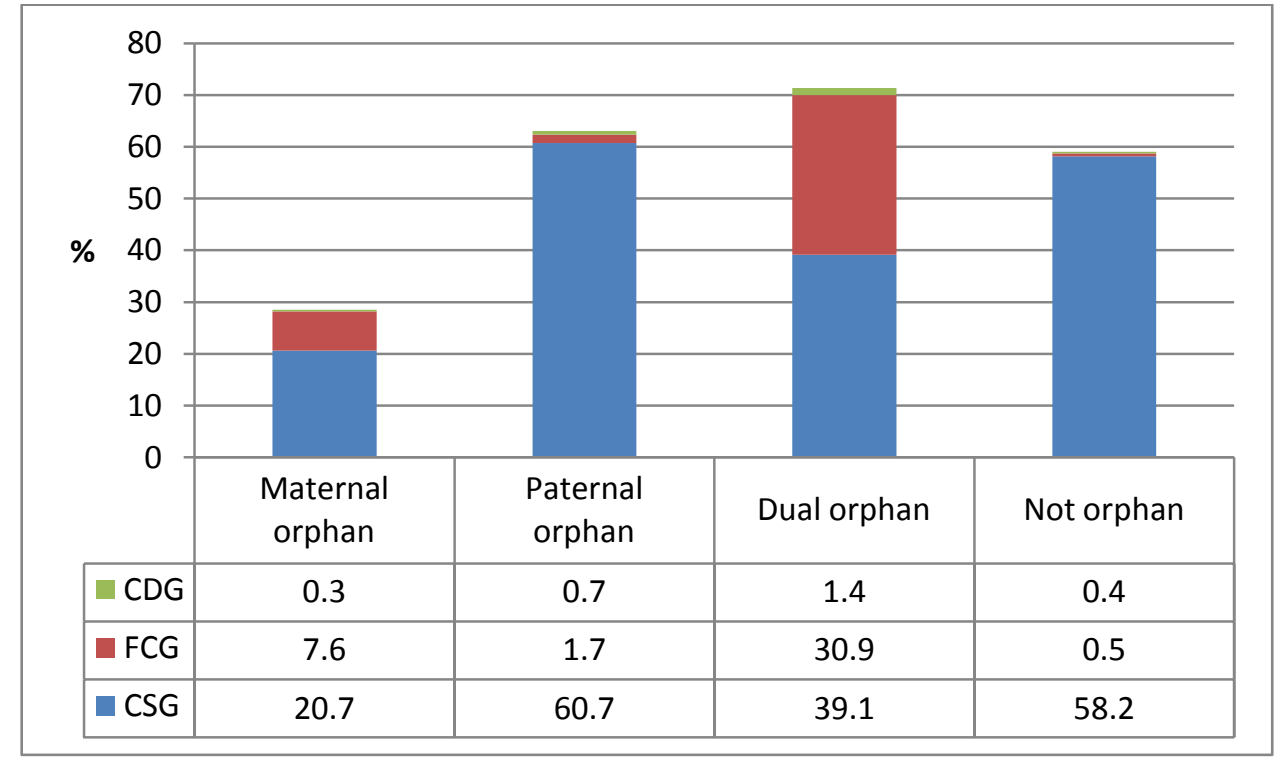

The next section explores further the different demographics of the Child Support Grant and the Foster Care Grant respectively.

\subsection{Child Support Grant}

The Child Support Grant accounts for the vast majority of child grants in the data (94\%). Adjusted to resemble national population figures, 8,225,215 children receive the Child Support Grant. SASSA reports the number of children receiving a Child Support Grant in October 2008 as $8,370,324$, which means the NIDS figures are a remarkably accurate representation of those receiving the Child Support Grant. 
Two main issues for the effectiveness of the child support grant remain children in need who are not receiving it and ineligible children/adults who are receiving it illegally. Figure 2 below illustrates the difference by age between the number of children reported by SASSA and by NIDS. The two trend lines show broadly similar trends across ages.

Figure 2: Number of children receiving Child Support Grants

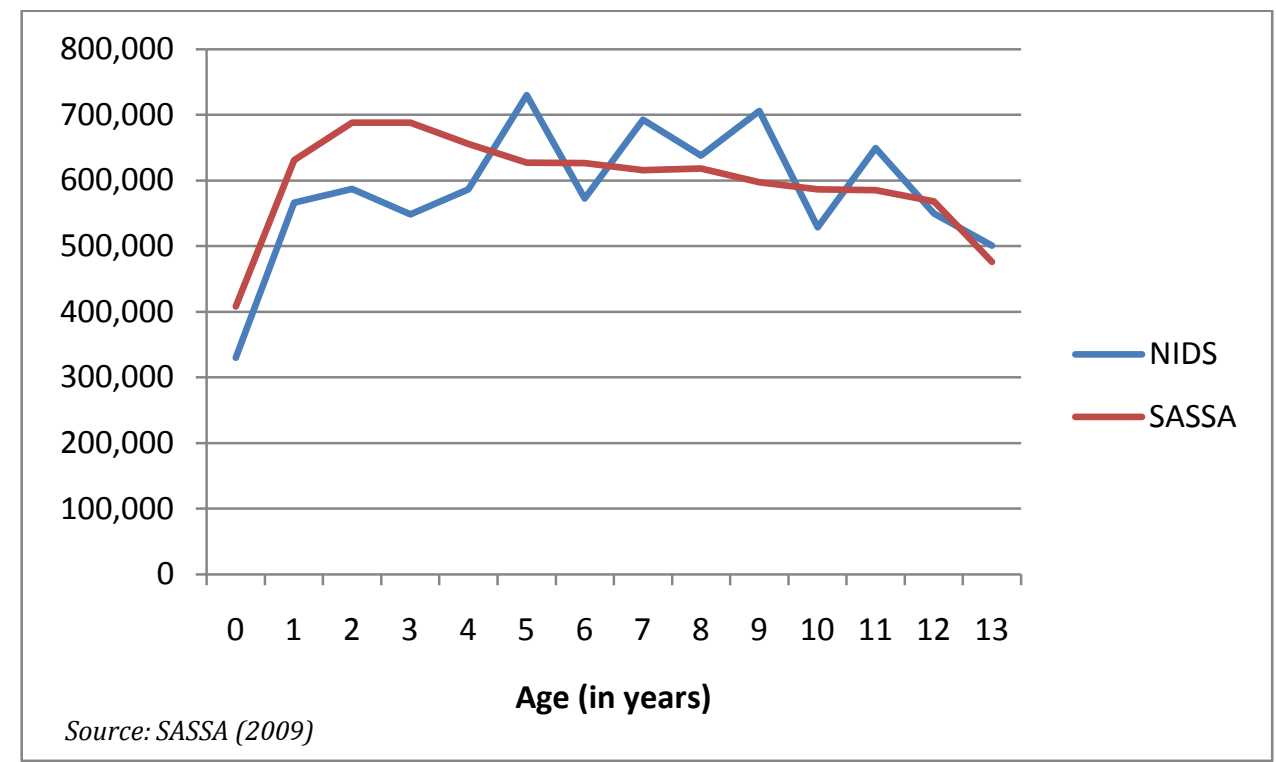

Among those reporting receipt of a grant there could also be children who should not be receiving it. We did a simple simulation to estimate how many children were eligible to receive the child support grant based on the means test and the age limit. Table 2 below compares our estimates of eligibility with the number of respondents reporting receipt of the grant. The simulation suggests that 153,404 children who are not eligible are benefiting from the grant. This is not entirely surprising given that the means test is only administered at the time of initial application and a caregiver's income will vary over time.

Table 2: Cross-tabulation of eligibility and response

\begin{tabular}{ccccc} 
& \multicolumn{4}{c}{ Grant reported } \\
Eligible for CSG & CSG & FCG & CDG & Nothing \\
\hline Yes & $6,634,968$ & 206,894 & 52,513 & $2,805,246$ \\
No & 153,404 & 30,211 & 1,130 & $1,854,097$ \\
\hline
\end{tabular}

On the other hand there appear to be 2,805,246 children in need who are not receiving the grant. Of these, 2,190,526 have never applied for a grant, the reasons are listed in Figure 3 below. The most common reason for not applying when eligible was stated as a lack of correct documentation. This has been a problem throughout the history of the child support grant and 
was cited as the most common cause of non-application in the KwaZulu-Natal Income Dynamics Survey of 2004, although the percentage of respondents citing this problem has decreased a lot. Figure 4 below plots the prevalence of the two most cited reasons for non-application by age. It is apparent that documentation is the most pressing issue in the younger ages and high income in the older ages. This is to be expected as caregivers often delay document application when a child is born or have to wait many months to receive it when they do.

Figure 3: Main reason grant was not applied for

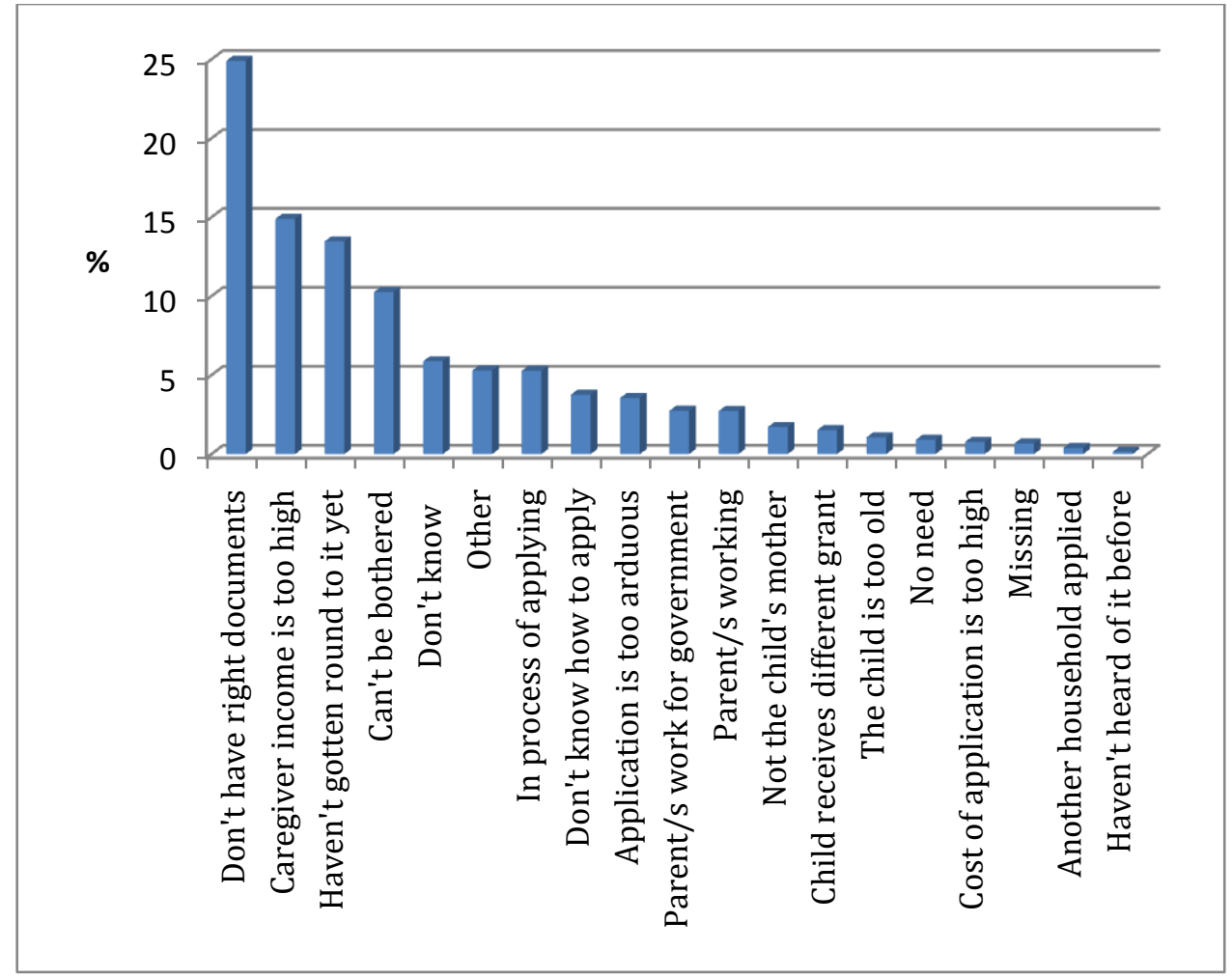

Figure 4: Main reason grant was not applied for by age

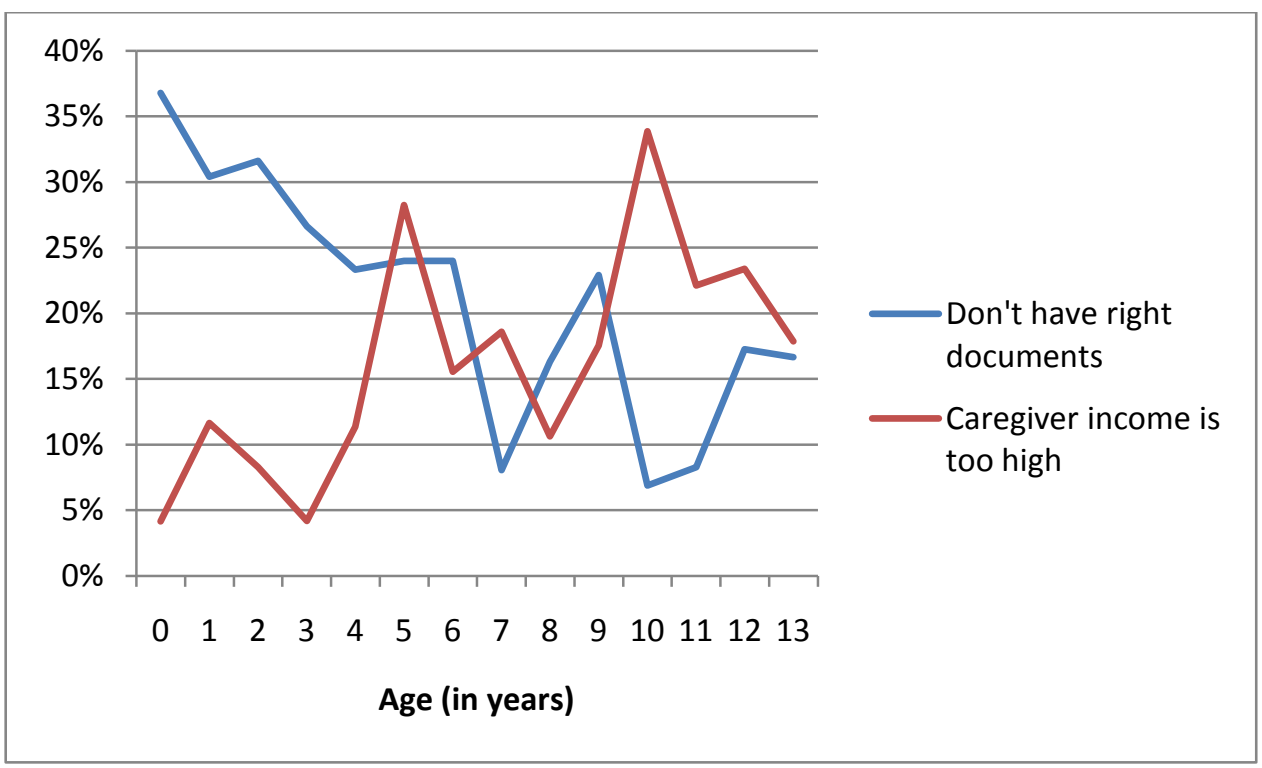


The means test level of income was adjusted upwards in October 2008 to include more children in need. Figure 5 below illustrates the number of children eligible under the new and old means test levels by age. Under the new definition there are an additional 1,798,950 children now considered eligible for the grant, an increase of $21.9 \%$.

Figure 5: Simulated number of eligible children under the different means tests

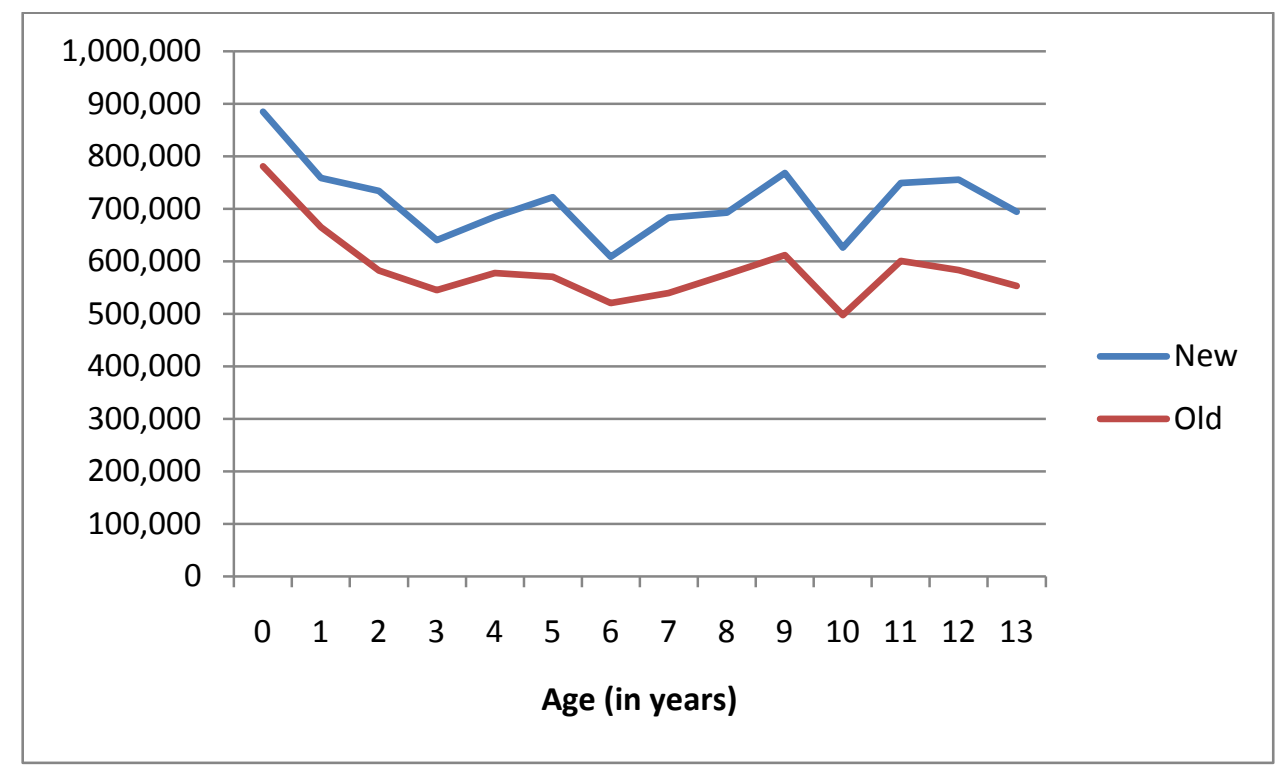

Race is no longer listed in data from the South African Social Security Agency so comparisons cannot be made. Kruger (1998) states $0.2 \%$ of African children, $1.5 \%$ of White children, $4 \%$ of Indian children and 4.8\% of Coloured children received the state maintenance grant in 1990. The NIDS data shows that $61 \%$ of African children, $2 \%$ of White children, $15 \%$ of Indian children and $30 \%$ of Coloured children under 14 received the child support grant in 2008 . This shows a massive increase in the coverage of social assistance for children over the last 18 years, particularly for African children.

Figure 6 below illustrates just how closely the NIDS data follows the same trends as the SASSA data. The only discrepancies are a slight undercount in the Western Cape, Northern Cape and North-West and a slight over count in Gauteng. Kwa-Zulu Natal shows the highest number of grant recipients at more than 2 million children, while the Northern Cape shows the lowest at under 200,000 children. Table 3 below shows the percentage of grant recipients by province to better illustrate poverty proportional to population size. Limpopo shows a high proportion of children receiving the child support grant, at more than two thirds, while Western Cape shows the lowest proportion, at less than a third. 
Figure 6: Child support grant beneficiaries by province

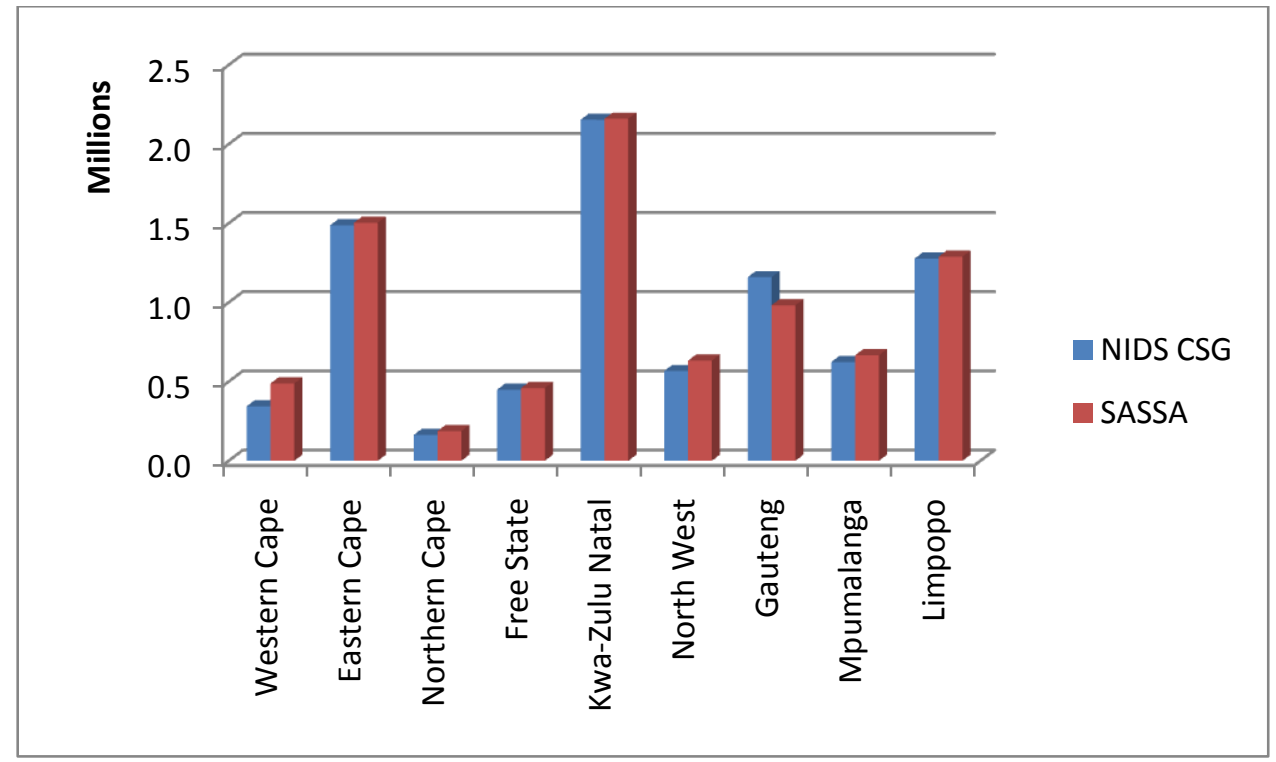

Table 3: Proportion of children receiving grants by province

\begin{tabular}{lcc}
\multicolumn{1}{c}{ Province } & Freq. & $\%$ \\
\hline Western Cape & 393,614 & 29.2 \\
Eastern Cape & $1,575,612$ & 66.9 \\
Northern Cape & 184,149 & 56.6 \\
Free State & 470,924 & 55.5 \\
Kwa-Zulu Natal & $2,296,616$ & 64.6 \\
North West & 594193 & 59.4 \\
Gauteng & $1,248,525$ & 48.4 \\
Mpumalanga & 643,131 & 55.8 \\
Limpopo & $1,324,575$ & 70.7 \\
\hline
\end{tabular}

NIDS (2009)

The majority $(77 \%)$ of the recipients of the child support grant are reported as the child's parents. Another $9 \%$ are reported as the child's grandparents. Unfortunately there are a number of errors in the data regarding the child's relationship to the grant recipient. Just under $2 \%$ of the respondents claimed relationships that are implausible such as 'spouse', 'child', 'grandchild' or even 'great-grandchild'. It is likely that the respondent or interviewer misunderstood the question and listed the child's relationship to the caregiver, as opposed to the caregiver's relationship to the child. This is not a significant proportion of the sample but the potential for error needs to be noted. Roughly $17.5 \%$ of caregivers receiving social assistance for children are not co-resident with them. The vast majority of these non-resident grant 
recipients are the child's parents. This figure shows an increase in non-resident grant recipients when compared to the KIDS 2004 estimate of 9.9\% (Woolard, Carter \& Aguero, 2005).

\subsection{Foster Care Grants}

Foster care grants comprise a much smaller proportion of the sample and thus not as much analysis can be done as for the child support grant. Only 312,458 children under the age of 15 reported receiving the foster care grant in 2008. Unfortunately the NIDS survey does not contain grant information on children aged 15 and above. Figure 7 below shows the number of foster care grant recipients by age. Foster care grant recipients are expected to increase with age as the majority are orphans and the probability of a child becoming an orphan increases with age. See Table 4 below for the proportions of orphans receiving foster care grants. Only $20.6 \%$ of foster care grant recipients are not orphans and are thus assumed to have living parents unable to care for them.

\section{Figure 7: Age distribution of children receiving foster care grant}

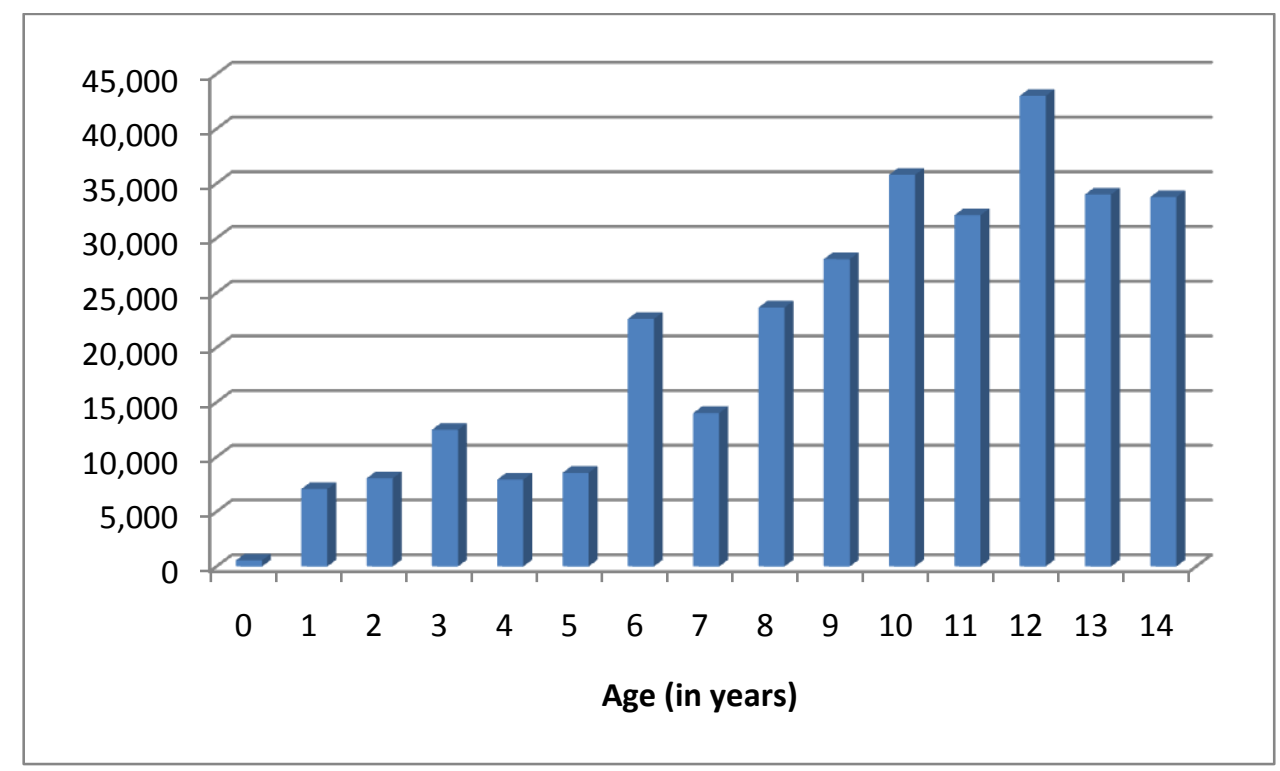

Table 4: Orphanhood status of foster care grant recipients

\begin{tabular}{lcc}
\multicolumn{1}{c}{ Orphanhood status } & Freq. & $\%$ \\
\hline Mother dead & 66,259 & 21.2 \\
Father dead & 29,851 & 9.6 \\
Both dead & 134,836 & 43.2 \\
Neither dead & 64,361 & 20.6 \\
Missing & 17,151 & 5.5 \\
\hline Total & 312,458 & 100
\end{tabular}


Figure 8 below illustrates the extent of the foster care grant penetration in each province. Northern Cape possesses the largest proportion of foster care grant recipients, with Mpumalanga possessing by far the least. It is, at present, unclear why there are so few foster care grant recipients in Mpumalanga. NIDS data on the relationship of the caregiver to the child suggests that many foster care grant recipients do not actually qualify for the grant. Grandparents were listed as the caregiver in 34\% of respondents, parents accounted for $13 \%$ and foster parents only accounted for $11 \%$. A high proportion (6\%) also listed implausible caregivers such as children and grandchildren. As with the child support grant, there is likely to be a great deal of confusion and miscommunication around this particular variable.

Figure 8: Proportion of children under 15 receiving the foster care grant

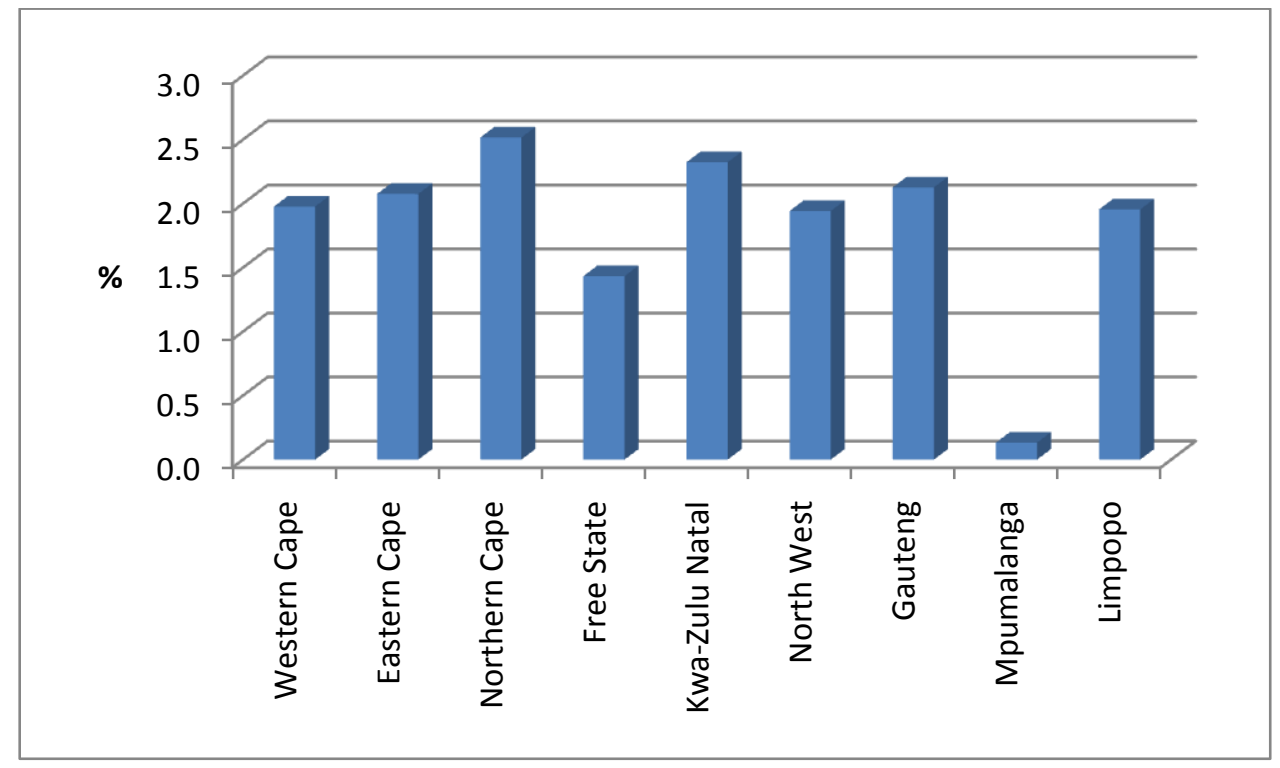




\section{Social Assistance for the Elderly}

This section profiles recipients of the old age pension as reported in the NIDS dataset, and provide comparisons to data provided by the South African Social Security Agency (SASSA). The Old Age Pension (OAP) is a non contributory cash transfer to pensioners who qualify as 'in need'. It is worth noting that South Africa and Brazil are the two countries with the largest noncontributory pension programmes in the world. Benefits associated with non-contributory pension programmes include poverty reduction among the elderly and their households, the facilitation of investment in human and physical capital within beneficiary households, the strengthening of intergenerational solidarity and transfers, insurance against the adverse effects of agricultural reform in poorer rural communities, and the encouragement of local economy activity. (Barrientos, 2003).

The majority of NIDS interviews were conducted in March and April 2008, and comparison figures used are all dated April 2008, unless specifically indicated otherwise. As with the previous analysis all figures have been weighted using the NIDS dataset post-stratified weight (w1_wgt).Where age and race are shown in this report, the individually derived best measures of age (w1_best_age_years) and race (w1_best_race) are used.

\subsection{Eligibility}

At the time of the survey one must be 60 years or older if female and 63 years or older if male in order to qualify for an old age pension. As with the disability grant, the individual concerned cannot be maintained or cared for in a state sponsored institution or be a recipient of any other grant. (SASSA, 2009).

Recipients of the grant must pass a means test, consisting of an asset criterion and income criterion, in order to be considered eligible. In general however, due to difficulties with the valuation of assets, only the income criterion is applied in practice when evaluating the means test. (SASSA, 2009).

\subsection{Demographics of Grant Beneficiaries}

Table 5 below shows that 616,280 (28.7\%) of the total 2147522 age-eligible grant recipients reported are men and 1,531,242 (71.3\%) are women. This is to be expected given the longer life expectancy of women as well as lower labour force participation rates among women. Some individuals reported receipt of the disability grant, but were of pensionable age and these 
individuals are included in the total number of age eligible pension recipients of 2,147,522. SASSA reports the number of grant recipients as 2,234,454 in April 2008 which is very close to the NIDS estimate.

Table 5: Eligibility of reported old age pension recipients

\begin{tabular}{lccc}
\multicolumn{4}{c}{ Receiving old age pension } \\
& Male & Female & Total \\
\hline Age Eligible* & 616,280 & $1,531,242$ & $2,147,522$ \\
Age Ineligible & 125,781 & 196,880 & 322,661 \\
Age Unknown & 6,591 & 42,770 & 49,361 \\
\hline Total Recipients & 748,652 & $1,770,892$ & $2,519,544$ \\
*Includes people reporting disability grants but of pensionable age
\end{tabular}

Part of the age eligibility error may be due to individuals receiving a disability grant and referring to it generically as a "pension". Reclassifying grants earned by individuals who report having a disability does not have a large impact on the number of age ineligible individuals who report receipt of a state sponsored pension (see Table 6 below). Only about $22 \%$ of the age ineligible pension recipients were disabled and likely to have misreported the type of grant they receive from the state.

Table 6: Disability in age ineligible pension recipients

\begin{tabular}{lllllll} 
& Male & & Female & \multicolumn{2}{c}{ Total } \\
& Freq. & $\%$ & Freq. & $\%$ & Freq. & $\%$ \\
\hline $\begin{array}{l}\text { Self-Reported } \\
\text { disability }\end{array}$ & 35,524 & 28.2 & 34,022 & 17.3 & 69,546 & 21.6 \\
Not disabled & 90,257 & 71.8 & 162,858 & 82.7 & 253,115 & 78.4 \\
\hline Total & 125,781 & 100 & 196,880 & 100 & 322,661 & 100
\end{tabular}

The majority of state pensions paid to men occur soon after they initially become eligible for pension, and tails off sharply beyond the age of 70 . 
Figure 9: Proportion of old age pension recipients by age and gender

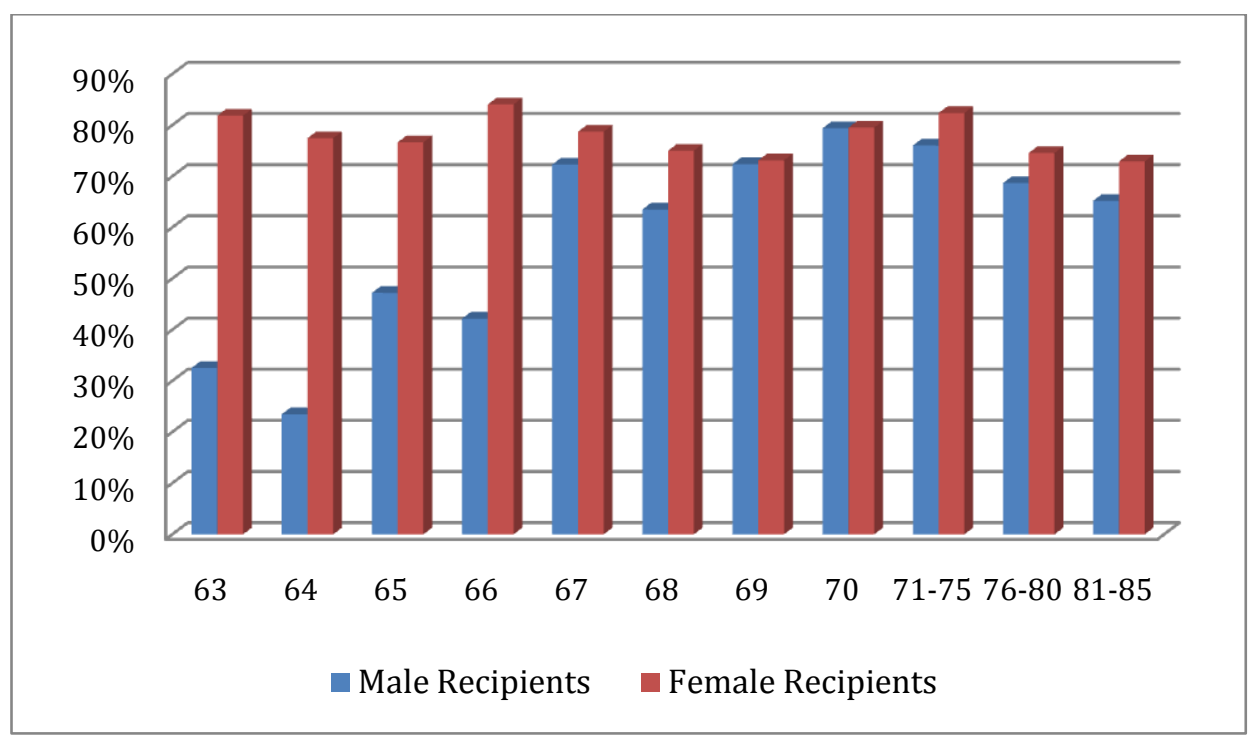

Unfortunately, comparison figures for the distribution of pension by age and gender were not available from SASSA at the time of writing, but Figure 10 below shows a comparison of the distribution of grants by province. The provincial distributions match one another very closely. While there is some variance in the total number of grants in each province, and the relative share of each province, this discrepancy is relatively small and the rank of each province in terms of pension receipt is the same in both sets of data.

Figure 10: Distribution of old age pension by province

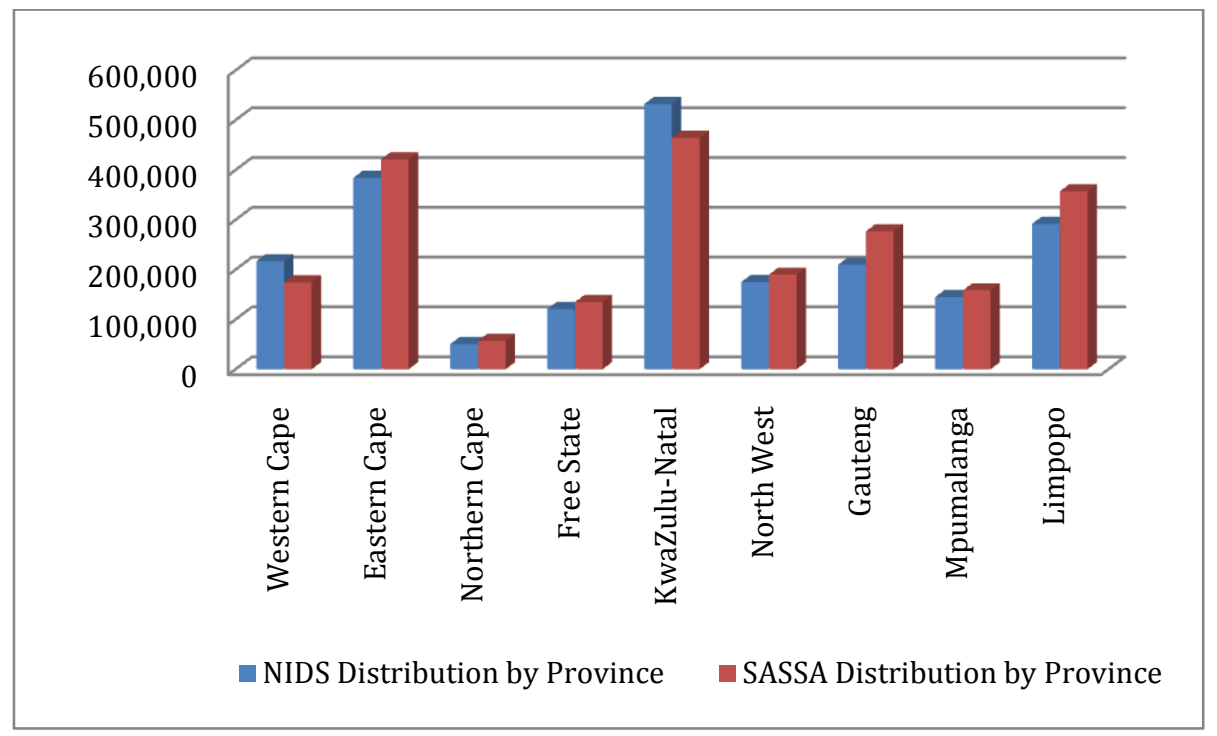

Table 7 below shows the distribution of age-eligible reported pension recipients by race. Government statistics of grant receipt by race are no longer made available so comparisons unfortunately cannot be made. Of the age eligible African population $86 \%$ are in receipt of state 
pensions, which matches patterns described by Barrientos (2003). As Africans comprise the largest and poorest share of the South African population it is unsurprising that they receive the overwhelming majority of state pensions. Coloureds also have a relatively high number of ageeligible pension recipients. The initial sample size for the Asian/Indian and White populations are relatively small, only 31 and 60 observations respectively, so these figures are unlikely to be representative. That said, given the relative affluence of the White population, the comparatively low ratio pension receipt is to be expected.

Table 7: Old age pension by population group

\begin{tabular}{|c|c|c|c|c|c|}
\hline \multirow{2}{*}{$\begin{array}{l}\text { Race } \\
\text { African }\end{array}$} & \multicolumn{2}{|c|}{ Actual recipients } & \multicolumn{2}{|c|}{ Age-Eligible } & \multirow{2}{*}{ 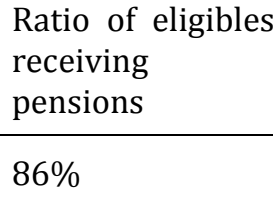 } \\
\hline & $1,641,081$ & $77.23 \%$ & $1,907,388$ & $63.16 \%$ & \\
\hline Coloured & 211,945 & $9.97 \%$ & 257,171 & $8.52 \%$ & $82 \%$ \\
\hline Asian/Indian & 85,006 & $4.00 \%$ & 104,471 & $3.46 \%$ & $81 \%$ \\
\hline White & 186,764 & $8.79 \%$ & 751,053 & $24.87 \%$ & $25 \%$ \\
\hline Total & $2,124,796$ & $100 \%$ & $3,020,083$ & $100 \%$ & $70 \%$ \\
\hline
\end{tabular}




\section{Social Assistance for the Disabled}

There are three different forms of social assistance for the disabled depending on their age. Up until the age of 18 , disabled children are entitled to receipt of the Care Dependency Grant provided their caregivers are judged 'in need' by a means test. From 18 years until retirement age, disabled adults are entitled to the Disability Grant if they qualify according the same means test applied to the OAP. Once disabled individuals become old enough to be eligible for pensions, their disability grants are converted to old-age pensions, provided they continue to meet the requirements of the means test. The value of the disability grant and old age pension is the same. (SASSA, 2009)

This section will profile recipients of the disability grant as reported in the NIDS dataset, and compare to data provided by the South African Social Security Agency (SASSA). The Disability Grant (DG) is a non contributory form of social assistance paid to working-aged individuals who suffer from disabilities that severely limit their capacity to work. Once again, comparison figures used are all dated April 2008, unless specifically indicated otherwise and all figures presented in this section have been weighted using the NIDS dataset post-stratified weight (w1_wgt).

\subsection{Eligibility}

As with the OAP, in order to qualify for the disability grant the individual concerned cannot be maintained or cared for in a state sponsored institution, or be a recipient of any other grant (SASSA, 2009). In addition to the income means test, in order to qualify for a disability grant one must be between the ages of 18 and 59 if female, and 18 and 62 if male. Medical confirmation of the existence of a disability is required, and the individual cannot be maintained or cared for in a state sponsored institution. Finally, one may not hold any other social grant aside from the disability grant (SASSA, 2009).

\subsection{Demographics of Grant Beneficiaries}

There are a total of 1,356,667 individuals who report receipt of a disability grant in the NIDS dataset. However, not all of the reported disability grant recipients fall inside the age-eligible bracket. As the value of the disability grant is the same as the state pension, recipients of pensionable age are reclassified as pensioners and their disability grants are converted to old age pensions. This leaves relatively small percentages of men and women who report earning disability grants as age-ineligible, $3.6 \%$ and $1.1 \%$ respectively. This is largely due to individuals younger than the minimal threshold reporting receipt of the disability grant. In this situation 
these individuals are most likely receiving the Care Dependency Grant (which is a disability grant for children under 18). The total number of reported age-eligible disability grant earners in NIDS is therefore $1,220,738$ which is very close to the SASSA figure of 1,141,049 total permanent disability grant recipients.

Table 8: Eligibility of disability grant recipients

\begin{tabular}{llll}
\multicolumn{4}{c}{ Receiving disability grant } \\
& Male & Female & Total \\
\hline Age Eligible* & 485,550 & 735,188 & $1,220,738$ \\
Age Ineligible & 38,559 & 49,346 & 87,905 \\
Age Unknown & 10,693 & 8,743 & 19,436 \\
\hline Total Recipients & 534,802 & 793,277 & $1,328,079$ \\
*includes disabled pension recipients not at pensionable age
\end{tabular}

A total of 2,007,175 respondents who are age eligible for the disability grant reported suffering from disability or illness. This figure is much larger than the 1,290,284 reported disability grant recipients. Only 473,928 (24\%) of those who report disability or illness report the specific type of disability they suffer from. The physically disabled amount to 223,288 and the sight, hearing or speech impaired to 250,640 respondents. Thus it is difficult to compare the number of disability grant recipients with the number of disabled within the NIDS data due to problems with non-response.

Figure 11 below compares the provincial distribution of disability grants received by ageeligible respondents in the NIDS dataset to SASSA figures. In general, the numbers captured in the NIDS dataset are a slight overestimate of the grants paid by SASSA, with the notable exception of the Eastern Cape where SASSA data indicates almost twice the number of grants. 
Figure 11: Distribution of disability grant by province

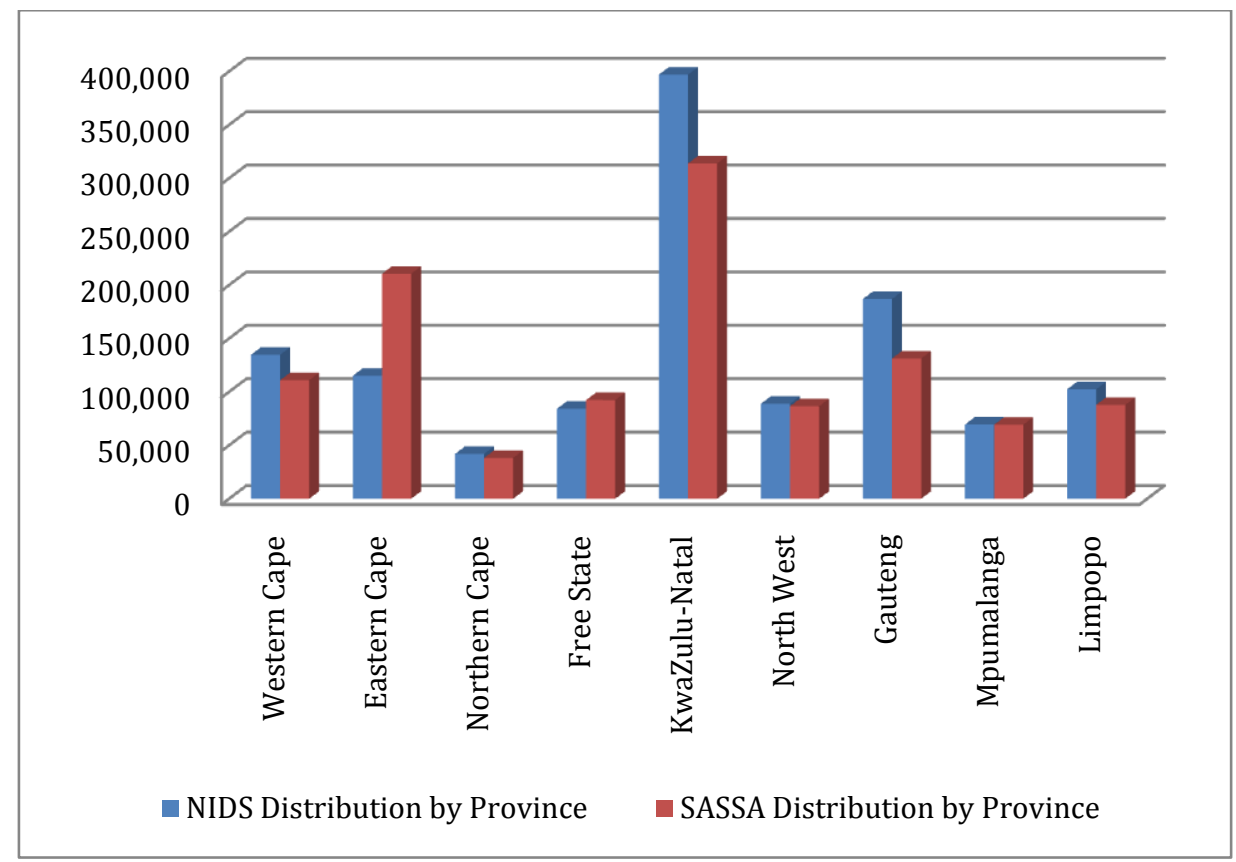

Table 9: Disability grant by province

\begin{tabular}{|l|l|l|}
\hline \multicolumn{3}{|l|}{ NIDS * } \\
\hline Province \\
\hline Western Cape & 134693 & $11.03 \%$ \\
\hline Eastern Cape & 115196 & $9.44 \%$ \\
\hline Northern Cape & 41888 & $3.43 \%$ \\
\hline Free State & 84152 & $6.89 \%$ \\
\hline KwaZulu-Natal & 397066 & $32.53 \%$ \\
\hline North West & 88922 & $7.28 \%$ \\
\hline Gauteng & 187008 & $15.32 \%$ \\
\hline Mpumalanga & 69460 & $5.69 \%$ \\
\hline Limpopo & 102353 & $8.38 \%$ \\
\hline & & \\
\hline *Age eligible only & 1220738 & $100 \%$ \\
\hline
\end{tabular}

\begin{tabular}{|l|l|l|}
\hline \multicolumn{3}{|l|}{ SOCPEN } \\
\hline \multicolumn{3}{|l|}{ Province } \\
\hline Western Cape & 110869 & $9.72 \%$ \\
\hline Eastern Cape & 210624 & $18.46 \%$ \\
\hline Northern Cape & 38244 & $3.35 \%$ \\
\hline Free State & 92351 & $8.09 \%$ \\
\hline KwaZulu-Natal & 313893 & $27.51 \%$ \\
\hline North West & 86674 & $7.60 \%$ \\
\hline Gauteng & 131311 & $11.51 \%$ \\
\hline Mpumalanga & 69257 & $6.07 \%$ \\
\hline Limpopo & 87826 & $7.70 \%$ \\
\hline & & \\
\hline & 1141049 & $100 \%$ \\
\hline
\end{tabular}

Table 10 below details the distribution of disability grants by race. The bulk of disability grants are paid to Africans because they comprise the biggest share of the population. When one looks at the number of grants paid by race in relation to the share of the population comprised by that race, it is apparent that Africans do not receive a relatively high percentage of disability grants. Given the small sample size of the Indian/Asian and White populations the numbers below could be unreliable. Government statistics of grant receipt by race are no longer made available so unfortunately comparisons cannot be made in this regard. However, the relatively high rate 
of disability grant receipt in relation to total age eligible population may be a vestige of the racial discrepancies present in the receipt of grants noted historically (van der Berg, 2001 cited in Woolard, 2003).

Table 10: Disability grant by race

\begin{tabular}{|c|c|c|c|c|c|}
\hline \multirow{2}{*}{$\begin{array}{l}\text { Race } \\
\text { African }\end{array}$} & \multicolumn{2}{|c|}{ Actual recipients } & \multicolumn{2}{|c|}{ Age-Eligible population } & \multirow{2}{*}{$\begin{array}{l}\text { Ratio of population } \\
\text { receiving grants }\end{array}$} \\
\hline & 922504 & $75.7 \%$ & 18989231 & $78.1 \%$ & \\
\hline Coloured & 152082 & $12.5 \%$ & 2181570 & $9.0 \%$ & $7.0 \%$ \\
\hline Asian/Indian & 49869 & $4.1 \%$ & 679372 & $2.8 \%$ & $7.3 \%$ \\
\hline White & 94513 & $7.8 \%$ & 2450624 & $10.1 \%$ & $3.9 \%$ \\
\hline Total & 1218968 & $100 \%$ & 24300797 & $100 \%$ & $5.0 \%$ \\
\hline
\end{tabular}




\section{Social Grants as a Source of Income}

Table 11 looks at the percentage of households in each income quintile that receive any income from social grants. It is immediately evident that the grants reach poorer households, with more than half of households in the bottom quintile receiving some income from the CSG, in comparison with only $9 \%$ of households in the top quintile. Interestingly, households receiving the Old Age Pension are more likely to be in the second and third quintile rather than the very poorest quintile.

Table 11: Percentage of households reporting income from social grants, by quintile

\begin{tabular}{llll} 
Quintile & $\begin{array}{l}\% \text { reporting any income } \\
\text { from Child Grants }\end{array}$ & $\begin{array}{l}\% \text { reporting any income } \\
\text { from Disability Grant }\end{array}$ & $\begin{array}{l}\% \text { reporting any income } \\
\text { from OAP }\end{array}$ \\
\hline 1 & $55.8 \%$ & $5.7 \%$ & $9.8 \%$ \\
2 & $57.9 \%$ & $10.9 \%$ & $27.1 \%$ \\
3 & $45.4 \%$ & $14.7 \%$ & $23.5 \%$ \\
4 & $26.5 \%$ & $9.9 \%$ & $17.7 \%$ \\
5 & $9.0 \%$ & $2.8 \%$ & $5.0 \%$ \\
\hline All & $33.6 \%$ & $8.2 \%$ & $15.3 \%$
\end{tabular}

In Figure 12 we disaggregate household income sources by income quintile in order to highlights the role of social assistance grants in providing income support to the poorest households. It is striking that fully two-thirds of income to the bottom quintile comes from social assistance grants, with most of this income coming from child grants (CSG, FCG and care dependency combined). As one moves up the income distribution, labour market income becomes increasingly important and reliance on social assistance is commensurately reduced. 
Figure 12: Sources of cash income, by quintile

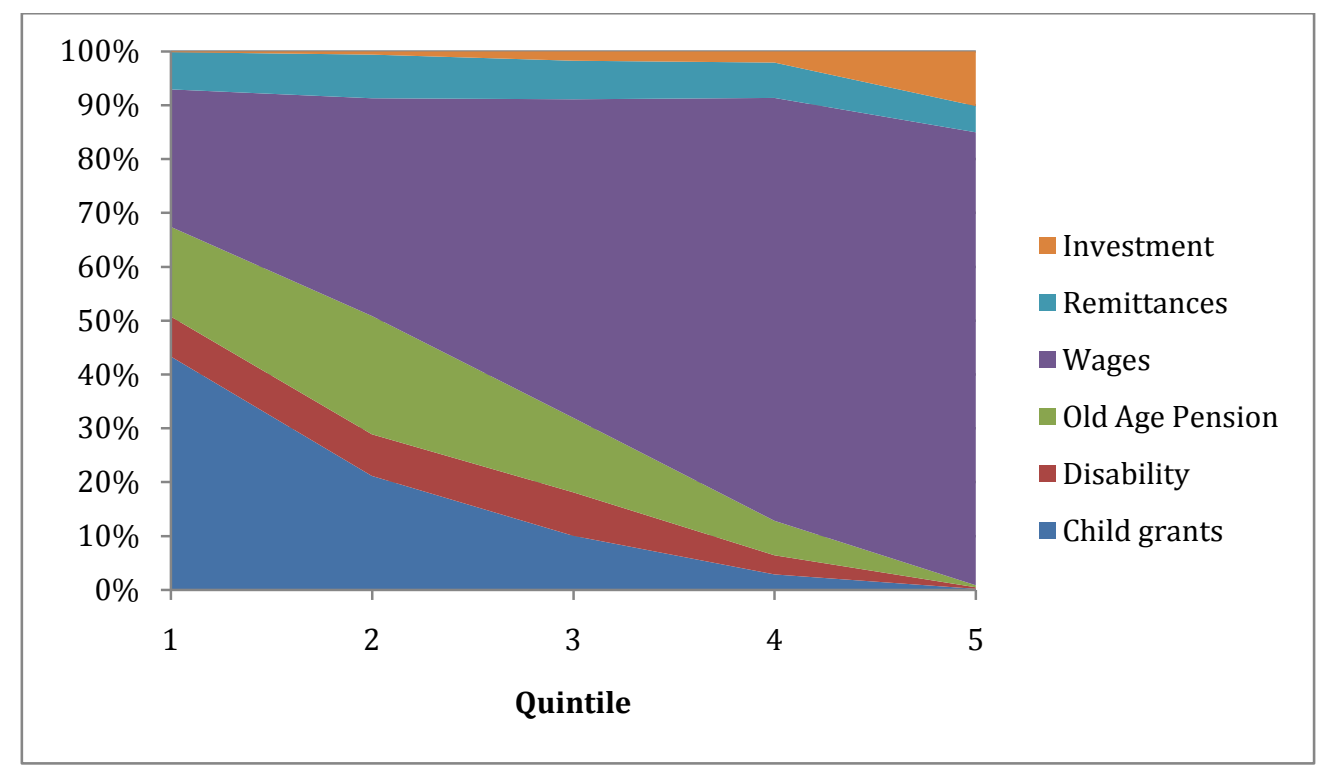

Note: this figure excludes imputed income from owner-occupied housing 


\section{Conclusion}

This paper has begun to scratch the surface of what NIDS can tell us about the extensive system of social assistance in South Africa. The paper has shown that the number of CSG and OAP beneficiaries broadly matches the number of beneficiaries reported in the administrative data compiled by SASSA. It has also shown that interesting analysis of the grants (for example by the orphanhood status of children) is possible. Finally, the paper points to the important role of the grant system in providing income support and thereby reducing poverty in South Africa. 


\section{References}

Barrientos, A. 2003. What is the impact of non-contributory pensions on poverty? Estimates from Brazil and South Africa. Manchester: Institute for Development Policy and Management, University of Manchester.

Case, A., Hosegood, V. \& Lund, F. 2004. "The Reach of the Child Support Grant: Evidence from Kwa-Zulu Natal". CSDS Working Paper, 38.

Kruger, John. January 1998. From Single Parents to Poor Children: Refocusing South Africa's

Transfers to Poor Households With Children. Jerusalem: Paper to ISSA's 2nd International Research Conference on Social Security.

National Treasury of the Republic of South Africa. 2009. Budget Review. Pretoria.

South Africa Social Security Agency. 2009. You and Your Grants 2009. Available (online): http://www.sassa.gov.za/content.asp?id=1000000501, accessed: 4 July 2009.

Woolard, Ingrid. 2003. Impact of Government Programmes Using Administrative Datasets Social Assistance Grants. Ten Year Review Research Programme. Available (online): http://www.sarpn.org.za/documents/d0000946/P1041-Woolard_10year_June2003.pdf, accessed: 7 July 2009.

Woolard, Ingrid, Michael Carter \& Jorge Aguero. December 2005. Analysis of the Child Support Grant: Evidence from the Kwa-Zulu Natal Income Dynamics Study, 1993 - 2004. Report to the Department of Social Development. 


\section{Appendix}

Table 1: Non-response rates

\begin{tabular}{|c|c|c|c|c|c|c|c|c|c|c|}
\hline \multirow[b]{2}{*}{ Variable } & \multicolumn{2}{|c|}{ Response rate } & \multicolumn{2}{|c|}{ Don't know } & \multicolumn{2}{|c|}{ Refusal } & \multicolumn{2}{|c|}{ Missing } & \multicolumn{2}{|l|}{ Total } \\
\hline & Freq. & $\%$ & Freq. & $\%$ & Freq. & $\%$ & Freq. & $\%$ & Freq. & $\%$ \\
\hline $\mathrm{F} 1$ & 9,354 & 93.49 & 2 & 0.02 & 1 & 0.01 & 648 & 6.48 & 10,005 & 100 \\
\hline $\mathrm{F} 2$ & 5,805 & 98.27 & 1 & 0.02 & - & - & 101 & 1.71 & 5,907 & 100 \\
\hline F3_1 & 5,900 & 99.88 & - & - & - & - & 7 & 0.12 & 5,907 & 100 \\
\hline F3_2 & 5,514 & 93.35 & 11 & 0.19 & - & - & 382 & 6.46 & 5,907 & 100 \\
\hline F4_M & 3,066 & 51.90 & 2,720 & 46.05 & - & - & 121 & 2.05 & 5,907 & 100 \\
\hline F4_Y & 4,772 & 80.78 & 1,098 & 18.59 & - & - & 37 & 0.63 & 5,907 & 100 \\
\hline F5 & 3,433 & 99.59 & - & - & - & - & 14 & 0.41 & 3,447 & 100 \\
\hline F6_M & 112 & 32.94 & 220 & 64.71 & - & - & 8 & 2.35 & 340 & 100 \\
\hline F6_Y & 215 & 63.24 & 121 & 35.59 & - & - & 4 & 1.18 & 340 & 100 \\
\hline F7_M & 208 & 61.18 & 120 & 35.29 & - & - & 12 & 3.53 & 340 & 100 \\
\hline F7_Y & 302 & 88.82 & 29 & 8.53 & - & - & 9 & 2.65 & 340 & 100 \\
\hline F8 & 3,079 & 99.55 & 1 & 0.03 & - & - & 13 & 0.42 & 3,093 & 100 \\
\hline F9 & 2,591 & 94.26 & 148 & 5.38 & - & - & 10 & 0.36 & 2,749 & 100 \\
\hline F10_M & 207 & 62.72 & 101 & 30.61 & - & - & 22 & 6.67 & 330 & 100 \\
\hline F10_Y & 279 & 84.55 & 34 & 10.30 & - & - & 17 & 5.15 & 330 & 100 \\
\hline F11 & 310 & 93.94 & 1 & 0.30 & - & - & 19 & 5.76 & 330 & 100 \\
\hline F12 & 100 & 98.04 & 1 & 0.98 & - & - & 1 & 0.98 & 102 & 100 \\
\hline
\end{tabular}

The total column does not include observations which are not applicable to that question. 
Table 2: Variable names

Variable Definition

F1 Does anyone currently receive a grant for this child?

F2 What type of grant is this?

F3_1 Who is the person receiving the grant ( $p$-code)?

F3_2 Who is the person receiving the grant (relationship)?

F4_M When was this grant first received (month)?

F4_Y When was this grant first received (year)?

F5 Has anybody ever received a CSG for this child?

F6_M If yes, when was the grant first received (month)?

F6_Y If yes, when was the grant first received (year)?

F7_M If no longer receiving the grant, when did it stop (month)?

F7_Y If no longer receiving the grant, when did it stop (year)?

F8 Has anyone ever applied for a CSG for this child?

F9 If not, why not?

F10_M When was an application made (month)?

F10_Y When was an application made (year)?

F11 What was the outcome of the application?

F12 What was the reason the application was refused? 